\title{
A RACIONALIDADE DA JUSTIÇA
}

Bruno Amaro Lacerda*

1 Introdução. 2 Hans Kelsen: a justiça como legalidade. 3 Alf Ross: a justiça como regularidade. 4 Chaïm Perelman: o ato, a norma e o valor. $5 \mathrm{O}$ núcleo comum das três concepções. 6 Justiça, pessoa e reconhecimento. 7 Considerações finais. Referências.

\section{RESUMO}

Este artigo aborda a concepção de Hans Kelsen, Alf Ross e Chaïm Perelman sobre a justiça como regularidade na aplicação do direito e como valor subjetivo e irracional, no intuito de mostrar sua insuficiência como descrição da juridicidade. Diferentemente do afirmado pelos três autores, o direito deve se guiar por uma objetividade axiológica, a liberdade igual das pessoas ou dignidade, reconhecida reciprocamente na coexistência social. O menosprezo ou desconhecimento deste valor objetivo converte o direito em ordem injusta e funcionalista, sujeita a legitimar pretensões discriminatórias como expressões válidas de uma subjetividade não sujeita ao crivo da razão. $\mathrm{O}$ reconhecimento do homem como sujeito digno é uma exigência inafastável de racionalidade da justiça, sem a qual não se realiza a necessária vocação ética do direito.

Palavras-chave: Justiça. Pessoa. Reconhecimento. Dignidade.

\section{INTRODUÇÃO}

"Poucas ideias", diz Santiago Nino, "despertam tantas paixões, consomem tantas energias, provocam tantas controvérsias e têm tanto impacto em tudo o que os seres humanos valoram como a ideia de justiça". ${ }^{1}$ De fato, em seu desenrolar histórico, a justiça foi concebida de muitas maneiras: como mandamento divino, como virtude, como convenção, como garantia da liberdade etc. Praticamente todos os filósofos, dos pré-socráticos aos contemporâneos, tentaram compreendê-la e defini-la. Mas ela é também assunto frequente nas discussões do cotidiano, que envolvem pessoas sem pretensões teóricas, mas com interesse na vida prática e em sua correção moral. Trata-se, portanto, de um tema que diz respeito a todos.

Este artigo pretende investigar uma das mais relevantes questões que o tema suscita: a justiça é uma ideia racional ou, ao contrário, uma noção emocional e irracional como sustentaram alguns dos mais importantes filósofos do direito do último século? Justifica-se o problema porque, sem sua solução, não podemos estar

* Professor Adjunto da Universidade Federal de Juiz de Fora (UFJF). Doutor e Mestre em Filosofia do Direito pela UFMG. E-mail: brunoamarolacerda@gmail.com 
seguros sobre a objetividade dos nossos juízos de valor em questões de justiça. Afinal, qualificamos frequentemente pessoas, atos, normas e sistemas jurídicos como justos e injustos. Esta atitude tem sentido objetivo e, por conseguinte, pode ser veiculada por argumentos potencialmente aceitáveis por qualquer pessoa ou, no fundo, não passa de uma pretensão subjetiva, relativa a cada um de nós, que buscamos fraudulentamente universalizar?

Minha proposta é rever três autores que defenderam a irracionalidade da justiça como valor, a saber, Kelsen, Ross e Perelman, para na sequência apresentar uma visão crítica alternativa, restauradora da objetividade axiológica da justiça, por meio de sua conexão às noções de pessoa e de reconhecimento.

\section{HANS KELSEN: A JUSTIÇA COMO LEGALIDADE}

Para Kelsen, direito e justiça são conceitos que não se confundem, já que o primeiro designa uma técnica específica de organização social e o segundo um valor moral. Embora todo direito positivo se apresente como justo, é comum que nem todas as pessoas o enxerguem como tal, qualificando-o, ao contrário, como uma ordem injusta. Sendo assim, o que devemos entender por justiça?

Primariamente, a justiça é uma qualidade de uma ordem social e apenas secundariamente de um indivíduo, pois um homem é chamado "justo" quando sua conduta se conforma a um padrão dado pelas normas de um ordenamento. As normas de justiça, que integram esse ordenamento e impõem um padrão prescritivo, são para Kelsen um tipo específico de norma moral, cuja função é estabelecer um determinado tratamento de um indivíduo por outro. Neste sentido, a norma "não devemos suicidar-nos" é uma norma moral, mas não de justiça, pois não estabelece um tratamento de uma pessoa em face de outra: "Quer dizer: o suicídio pode ser considerado imoral, mas não injusto". ${ }^{2}$ Já a norma que incrimina o homicídio (proibindo que se mate alguém) é claramente uma norma moral de justiça. Mas quando um ordenamento, tomado como complexo de normas, deve ser considerado justo?

Uma interpretação possível é pensar que uma ordem normativa é justa quando permite que os homens alcancem a felicidade. Mas isto pode ser complicado, na medida em que as pessoas possuem concepções distintas do que as torna felizes e dos interesses que precisam perseguir para alcançar uma vida plenamente realizada. Elas também não entram em acordo sobre quais interesses merecem ser protegidos e quais devem ser desprezados, nem sobre a disposição hierárquica dos interesses escolhidos. Segundo Kelsen, isto ocorre porque questões envolvendo valores e interesses não podem ser respondidas por meio de um conhecimento racional, pois o que se busca nelas é um "juízo de valor determinado por fatores emocionais" ${ }^{3}$ e, neste sentido, válido apenas para o sujeito que o profere.

Qual valor é superior? A vida ou a honra da nação? Para os que acham que é a vida, alistar-se nas forças armadas e matar um inimigo na guerra pode 
ser o ato mais vil; para os partidários da honra, pode fazer sentido não apenas matar o inimigo na guerra, mas também sacrificar a própria vida caso isto seja necessário para a proteção da sociedade que se defende.

É claro que as pessoas podem discordar sobre qual valor é superior, o que ocorre com frequência. Mas esta discordância será sempre subjetiva e emocional; nunca poderá ser objetiva e racional e, assim, conduzir a um consenso científico: "É impossível decidir-se entre estes dois juízos de valor discordantes de uma maneira racional, científica. Em última instância, é nosso sentimento, nossa vontade, e não nossa razão; é um elemento emocional e não racional de nossa consciência que decide este conflito". ${ }^{4}$

Um juízo de valor, para Kelsen, é uma proposição com a qual se declara que algo é um fim último, um fim que não é meio para a realização de outro fim. Este juízo está inevitavelmente carregado de fatores emocionais e não pode ser comprovado pela experiência nem por um critério racional, ao contrário dos juízos de fato, que descrevem situações aferíveis empiricamente.

Isto, porém, não significa que cada indivíduo faça juízos de valor personalíssimos e, com eles, forme um sistema de valores próprio. Na vida prática, muitos indivíduos estão de acordo sobre seus juízos de valor e influenciam-se reciprocamente para o estabelecimento de sistemas éticos estáveis. Mas este fato de modo algum contradiz, para Kelsen, o caráter subjetivo e relativo dos juízos de valor. Esses acordos não provam que os juízos em questão são objetivos, do mesmo modo que a crença difundida por séculos de que o Sol girava em torno da Terra não foi suficiente para torná-la verdadeira.

Kelsen, no entanto, admite que a frequente associação da justiça com a paz pode revelar uma ideia fixa sobre o seu valor moral. Na impossibilidade de estabelecermos certos valores morais como absolutos (como pretendiam as teorias do direito natural), pode-se acreditar que um ordenamento que garanta a paz seja suficiente, mesmo que seja uma paz não esteada em valores absolutos. Deste modo, se o direito, ao garantir a paz, exerce uma função que é frequentemente chamada de "justa", pode-se dizer que "é justo aplicar o direito e injusto não aplicá-lo quando, por suas disposições, deva ser aplicado".5

O autor acaba, assim, aceitando a tese da justiça como legalidade (ou "legalidade da justiça"). Se a sociedade é melhor que a anarquia e a sociedade pacífica melhor que a beligerante, a paz é uma meta desejável. E esta só se viabiliza com o cumprimento do direito positivo, isto é, com a aplicação efetiva das suas disposições normativas. Assim, é "justo" que uma norma seja aplicada em todas as situações nas quais ela deva ser aplicada. E "injusto" que ela seja aplicada em um caso e não o seja em outro que também regule. Pode-se, deste modo, dizer que a justiça é justiça na aplicação do direito positivo: "A justiça, neste sentido, significa a manutenção de um ordenamento positivo mediante sua aplicação escrupulosa" . ${ }^{6}$

Como se vê, a justiça kelseniana não se refere ao conteúdo de uma ordem jurídica ou de suas normas, pois este conteúdo, como dito, está carregado de 
valorações que são emocionais e insuscetiveis de avaliação racional, mas ao seu modo de aplicação. Um ordenamento justo é aquele que deve ser aplicado segundo suas próprias disposições. Este é o único sentido de justiça que podemos considerar aferível cientificamente: "Só no sentido de legalidade pode o conceito de justiça ingressar na ciência do direito"?

\section{ALF ROSS: A JUSTIÇA COMO REGULARIDADE}

Ross observa que a justiça parece ser uma ideia simples, clara e com grande força motivadora. Todos parecem compreendê-la intuitivamente, mesmo as crianças. Além disso, todas as guerras e todos os conflitos políticos foram e continuam sendo travados em seu nome. Não há, como se sabe, quem se coloque explicitamente ao lado da injustiça. Todos os homens, organizações, sociedades e Estados julgam-se detentores da verdadeira justiça, na qual embasam e legitimam suas ações. Este fato deveria nos preocupar, diz ele, pois "desperta a suspeita de que algo está errado com uma ideia que pode ser invocada em apoio de qualquer causa". ${ }^{8}$

O autor admite, porém, que a justiça, como inúmeros filósofos e juristas afirmam desde a Antiguidade, está ligada à noção de igualdade. Esta conexão, no entanto, não se dá em sentido absoluto (pelo qual todos deveriam receber exatamente a mesma coisa), mas em seu sentido relativo, pelo qual os iguais (isto é, as pessoas que estão em uma situação igual) devem ser tratados da mesma maneira. Mas, para aplicação desta ideia de igualdade, é necessário que exista antes um critério que determine quais pessoas estão em condição igual. A demanda de justiça, deste modo, está direcionada não a todas as pessoas em geral, mas apenas a "todos os membros de uma classe determinada por certos critérios relevantes". ${ }^{9}$

Essa exigência de igualdade permite que se estabeleçam diferenciações entre pessoas que estão em circunstâncias ou condições diferentes, desde que embasadas em um critério relevante. Assim, uma norma pode ofertar tratamento especial à gestante, garantindo seu emprego por certo tempo, ou assegurar certos direitos não estendidos aos adultos às crianças e aos adolescentes. As normas fazem isto com frequência: selecionam certos critérios (idade, sexo, profissão etc.) a partir dos quais se formam determinadas classes de indivíduos às quais é reservado um tratamento diferenciado com base no critério escolhido.

Mas quais critérios são relevantes e quais não o são? Para esta pergunta não há uma resposta objetiva, diz Ross. A ideia de justiça não nos impõe quais critérios são adequados para diferenciar pessoas e quais são inadequados. Logo, a igualdade exigida pela justiça é apenas a correta aplicação de uma norma e seu critério a todos aqueles que estão sob sua incidência. Assim, pode-se dizer que é justo que quem está em situação igual a outra pessoa seja tratado igualmente a esta, e injusto que se estabeleça um tratamento desigual nas mesmas condições.

Por consequência, pode-se dizer que a justiça e a igualdade que lhe acompanha são simplesmente a "exigência formal de regularidade ou racionalidade" 
${ }^{10}$, isto é, que se aplique uma norma igualmente a todos os seus destinatários em conformidade com o critério que ela resguarda.

Disto, Ross conclui que a palavra "justiça” é adequada para descrever a conduta de um juiz ou de outro aplicador de uma norma que, em consonância com o critério normativo, trate pessoas que estão igualadas por certa circunstância de um modo similar. Isto não significa, todavia, que a justiça "necessite" de regularidade, mas mais corretamente que ela é regularidade: "Dizer que uma decisão é justa significa que foi feita de uma maneira regular, isto é, em conformidade com a regra ou sistema de regras vigentes". ${ }^{11}$

O termo, entretanto, não é apropriado para avaliar a própria norma que se deve aplicar regularmente. Quando referidas a uma norma, as palavras "justiça” e "injustiça” não possuem qualquer significação e, por esta razão, não são um guia confiável para o legislador. Assim, um juiz que aplique as normas jurídicas aos seus destinatários pode ter sua conduta descrita como justa, pois nela há regularidade, isto é, conformidade com as normas vigentes. Mas dizer que a própria norma é justa seria errôneo, pois indicaria uma qualidade axiológica objetiva discernível na própria norma, uma pretensão que Ross considera absurda.

Para o autor, então, se pode falar em justiça na aplicação regular das normas às situações concretas, mas jamais com referência à elaboração dessas normas. Na verdade, quando alguém qualifica uma norma como "justa" ou "injusta" está apenas comunicando uma expressão emocional. Assim, quando alguém diz "Sou contra esta regra porque ela é injusta", o que ele quer mesmo dizer é "Esta regra é injusta porque sou contra ela”. ${ }^{12}$

É neste contexto que se deve entender a conhecida passagem na qual Ross identifica o senso do justo com um soco em uma mesa: "Invocar a justiça é como dar um soco na mesa: uma expressão emocional que faz da própria exigência um postulado absoluto". ${ }^{13}$ É impossível, afirma o autor, empreender uma discussão racional sobre a justiça de uma norma, pois sempre será uma tentativa camuflada de persuasão ideológica e nunca uma verdadeira argumentação. A insistência nessas discussões sobre justiça e injustiça de normas, além de infrutífera (não passa de um choque de emoções), conduz ainda à intolerância e ao conflito, porque cada parte se preocupa apenas em impor sua concepção sobre a justiça normativa (isto é, sobre qual critério deve ser adotado por uma norma) e acaba permanecendo cego em relação aos outros interesses também presentes.

A justiça, portanto, não pode ser um critério para julgar uma norma. Mas isto não significa que não se possa falar em uma relação entre direito e justiça. Sem um mínimo de regularidade ou previsibilidade não se pode ter uma ordem jurídica. Assim, a ideia de justiça como exigência de regularidade na aplicação das normas integrantes dessa ordem pode ser dita "constitutiva" do direito. Essa regularidade, como oposta à arbitrariedade subjetiva, é em si mesma um valor; ela, porém, não se confunde com a justiça pensada como um valor objetivo de determinação necessária dos conteúdos das normas jurídicas integrantes dessa 
ordem, os quais, como reitera Ross, nada mais são que "a expressão de uma reação desfavorável perante ela”. ${ }^{14}$

Das afirmações do autor pode-se concluir que a justiça como exigência de regularidade na aplicação das normas é um valor racional que informa toda ordem jurídica e mesmo outras ordens normativas. A crença em um critério objetivo de justiça, que funcione como legitimador das normas jurídicas, ao contrário, é uma pretensão irracional que não se sujeita ao crivo de nenhuma discussão séria. Sempre será uma tentativa de impor uma visão de mundo em detrimento de outras igualmente possíveis. Por isto, "A ideologia da justiça não tem, pois, lugar em um exame racional do valor das normas". ${ }^{15}$

\section{CHAÏM PERELMAN: O ATO, A NORMA E O VALOR}

Se observarmos as intermináveis controvérsias que as pessoas têm sobre a justiça e os diferentes argumentos que elas apresentam nos debates sobre o assunto, notaremos sempre um mesmo pano de fundo, um acordo básico expresso na ideia de tratar do mesmo modo as pessoas que são iguais sob certo ponto de vista. Assim, a igualdade envolve sempre, diz Perelman, um tratamento equivalente dado às pessoas que estão equiparadas por um determinado aspecto. Esse tratamento é a ação que chamamos de justa. A justiça, deste modo, não é algo etéreo ou inalcançável, mas simplesmente o tratamento igual de seres humanos que se aproximam por uma "característica essencial".

É a presença dessa característica unindo as pessoas em uma categoria ou classe que determina o dever de tratamento igual dos seus componentes. Pense-se, por exemplo, em um professor que leciona para duas turmas de uma Faculdade de Direito, dando aulas de Direito Penal para uma e de Criminologia para a outra. O que diríamos se, no dia da avaliação, ele levasse a mesma prova para quarenta e nove alunos e somente uma prova diferente e bem mais fácil para $u m$ aluno da mesma turma de Direito Penal? Diríamos que ele praticou uma injustiça ao favorecer um aluno em detrimento de todos os demais. Em termos perelmanianos, o professor estaria tratando alunos que integram a mesma categoria essencial (uma mesma turma, cursando a mesma disciplina, dada pelo mesmo professor) de modo desigual, quando deveria tratá-los do modo mais aproximado possível, aplicando, senão a mesma prova, pelo menos provas diferentes de dificuldade similar.

Mas certamente não objetaríamos caso o professor levasse uma prova mais extensa e complexa que a que aplicou aos alunos de Direito Penal para seus alunos de Criminologia. Afinal, são provas de duas disciplinas com conteúdo diverso, cujos alunos compõem, sob este aspecto, duas categorias essenciais distintas e, portanto, não podem exigir um tratamento igual ao que foi dado aos alunos de Direito Penal (embora, é claro, possam exigir tratamento igual ao recebido pelos alunos da mesma turma que integram).

Com base nisso, Perelman estabelece uma fórmula de justiça que chamou de justiça formal ou abstrata, nestes termos: "um princípio de ação segundo o qual os seres 
de uma mesma categoria essencial devem ser tratados da mesma maneira". ${ }^{16}$ Esta definição é formal, pois não diz quando duas pessoas fazem parte de uma categoria essencial nem como devemos tratá-las. É uma espécie de ideia mínima de justiça, que traduz o acordo subjacente às inúmeras discussões que as pessoas travam sobre o assunto cotidianamente. Para fazer sentido, ela precisa ser contrastada com outras seis fórmulas de justiça chamadas de "concretas". São elas: a cada um a mesma coisa; a cada um segundo seus méritos; a cada um segundo seu trabalho; a cada um segundo as necessidades; a cada um segundo sua posição; a cada um o que a lei lhe atribui.

A ideia de Perelman é a seguinte: se a igualdade justa é a igualdade de tratamento das pessoas que compõem uma categoria porque possuem uma determinada característica em comum, as seis fórmulas concretas representam os critérios de determinação desse caractere e de formação da categoria correspondente (cujos membros farão jus ao tratamento igual).

Uma vez que aceitamos determinado critério como relevante e com base nele aproximamos pessoas, surge uma norma estipulando o dever de tratá-las como iguais. Norma inicialmente racional ou "regra da razão", nas palavras de Perelman. Assim, é a percepção de uma dada similitude entre pessoas (idade próxima, mesmo gênero, trabalho idêntico etc.), como fator que as identifica e une, que gera o dever racional, o qual pode, posteriormente, também ser convertido em dever jurídico.

É claro que a justiça reaparece, após o estabelecimento da norma jurídica, como a vontade de que a igualdade categorial prevista seja realizada, e por esse motivo se pode dizer com Widar Cesarini Sforza, em uma concepção próxima da de Perelman, que o princípio da justiça se revela "no preciso instante no qual aparece a vontade de que a classe seja realizada segundo a sua norma, isto é, no instante no qual a classe se realiza como volição de um tipo ou modelo de comportamento, com exclusão de qualquer outra classe". ${ }^{17} \mathrm{O}$ dever de justiça, destarte, inspira a elaboração da norma e guia posteriormente a sua aplicação.

Quando, porém, se questiona a justiça da própria norma, isto é, a justiça do valor que a norma realiza, é impossível dizer algo a respeito sem apresentar uma definição discutível do que é justo. E isto não pode ser feito a não ser de uma "maneira subjetiva", pois a justiça é "uma noção cujo sentido emotivo é muito pronunciado". ${ }^{18}$

Como não existe um sistema único de justiça (isto é, um sistema de valores considerados absolutamente justos), seu caráter arbitrário é inafastável. Disto resulta que, se uma determinada norma é considerada injusta por alguém que defende outra fórmula de justiça concreta ou a formação de uma categoria essencial mais ampla, mais restrita ou diversa, não há meios racionais para se decidir o conflito, restando apenas registrá-lo como existente. Estando instalada a pluralidade de valores, sua oposição e seu caráter arbitrário não permitem nenhuma solução racional, de modo que "um raciocínio será incapaz de dar ganho de causa a um ou a outro dos adversários". ${ }^{19}$ 
O máximo que se pode esperar da justiça é que ela seja regular, isto é, que se apliquem as normas regularmente aos casos aos quais elas se destinam, segundo a amplitude da categoria essencial e a fórmula de justiça concreta escolhida. Há, então, afirma Perelman, três elementos na noção de justiça: o valor que a funda, a regra que a enuncia e o ato que a realiza. Somente os dois últimos podem ser submetidos às exigências racionais. Assim, pode-se exigir que o ato seja regular, ou seja, conforme a regra, e que a regra não seja arbitrária, decorrendo logicamente do sistema de regras que se deve aplicar. Mas, quanto ao valor que funda o sistema normativo, "nós não podemos submetê-lo a nenhum critério racional, ele é perfeitamente arbitrário e logicamente indeterminado”. ${ }^{20}$

A justiça, portanto, é um ideal irracional apenas quando referida aos valores que sustentam as normas de um determinado ordenamento. Como exigência de regularidade dos atos e de aplicação das normas, ela é para Perelman a virtude racional por excelência. Mas a racionalidade da concretização normativa não pode conduzir equivocadamente à crença de que os valores normativos também seriam racionais. Deste modo, diz o autor, se pensarmos axiologicamente a ação dos aplicadores das normas, "é preciso não esquecer que sua ação é fundada sobre valores arbitrários, irracionais e aos quais se opõem outros valores em face dos quais um sentimento de justiça refinado não pode ficar inteiramente insensível". ${ }^{21}$

\section{O NÚCLEO COMUM DAS TRÊS CONCEPÇÕES}

As concepções de Kelsen, Ross e Perelman possuem um claro ponto em comum. Os três autores enxergam racionalidade na ideia de justiça, mas somente com referência à sua aplicação e não também em relação aos valores que as normas ou ordenamentos realizam. A justiça, embora com fundamentos e desenvolvimentos diversos, é para eles equivalente à regularidade. Um ato é justo quando se põe em conformidade com uma norma e uma norma é justa quando aplicada criteriosamente aos seus destinatários (a "classe" de Ross ou a "categoria essencial" de Perelman), segundo o padrão valorativo (o critério axiológico distintivo) que se busca realizar.

Deste modo, a pretensão de qualificar os valores normativos como justos ou injustos carece de sentido e não passa de uma atitude emocional que se simula como racional. Isto porque os valores, segundo os autores citados, são pretensões subjetivas e relativas que se chocam contra outras pretensões igualmente subjetivas e relativas, sem que se possa deduzir da razão um supremo valor que sirva como critério objetivo de validade moral e escalonamento dos interesses em colisão.

Esta concepção da irracionalidade da justiça como valor parece atrativa e convincente em um primeiro momento, mormente porque os três autores tangenciam um fato que experimentamos com frequência, o conflito de valores. Por exemplo, como deve ser compreendido o valor da liberdade individual? Este valor pode, em uma dada situação, ser superior e prevalecer sobre a vida? Continuando no exemplo, uma pessoa acometida por uma doença grave, que a 
impeça irreversivelmente de praticar as ações que mais prezava (como a prática de uma modalidade esportiva de alto rendimento) pode pretender legitimamente se matar? Ou exigir que outrem, como seu médico, faça isto por ela, praticando eutanásia? Ou, pelo contrário, a liberdade não pode jamais implicar violação da própria vida? Existe liberdade que implique sua auto-aniquilação? Em resumo, qual valor deve ser mais estimado, a vida ou a liberdade de escolha?

Os autores em questão diriam que esta última pergunta não tem sentido. Os valores são subjetivos e, deste modo, não se sujeitam a qualquer argumentação racional. Para alguns, o valor superior é a vida; para outros, a liberdade. Não há como afirmar racionalmente que é mais justo preferir um ao outro. E quando um ordenamento jurídico opta por um deles, proibindo, por exemplo, o auxílio ao suicídio e à eutanásia, a justiça aparece como exigência de concretização dessas normas proibitivas com regularidade. Somente esta regularidade na aplicação pode ser adequadamente chamada de "justiça".

Mas, por outro lado, o que diríamos de uma norma que estabelecesse uma diferenciação discriminatória, violadora da igualdade ontológica das pessoas, instituindo, por exemplo, uma política pública racista ou sexista? Partindo das propostas de Kelsen, Ross e Perelman, poderíamos dizer que essa norma agasalha um valor com o qual não concordamos, mas não teríamos como provar seu equívoco em razão da subjetividade e da relatividade dos valores em geral. Ou seja, em tese, seria possível que alguém defendesse a concepção oposta (de que esse tipo de norma, com conteúdo racista ou sexista, seria justa). Mas esta tese oposta não atingiria um valor objetivo, a liberdade igual das pessoas? Precisamos, para esclarecer a questão, ver o que outros filósofos, também do século passado, disseram sobre a conexão da ideia de justiça com as noções de pessoa e de reconhecimento.

\section{JUSTIÇA, PESSOA E RECONHECIMENTO}

Para Igino Petrone, filósofo italiano da virada do século XIX para o XX, se a primeira verdade do espírito é a consciência de si, a certeza cartesiana da minha existência como ser pensante, a segunda "é a certeza de que a minha consciência é correlativa às outras consciências coexistentes". ${ }^{22} \mathrm{O} e$ eu (ego) não é, então, afirmação pura e absoluta de si, mas um conceito de reciprocidade, comparativo e social, que se põe apenas na relação com o outro (alter), pela dimensão da alteridade.

A autoconsciência é dialética e bipolar: pensar-se como sujeito envolve necessariamente pensar os outros como sujeitos correlativos na vida social. Petrone denomina de "aspecto social da consciência de si" o fenômeno psíquico pelo qual o eu se coloca como subjetividade apenas quando se dispõe também a afirmar, por meio de um nexo de polaridade, o outro eu.

O direito nasce desse movimento de afirmação das subjetividades na coexistência, pelo qual as liberdades devem se limitar pelo reconhecimento recíproco. Por isto, a fórmula da justiça pode ser expressa deste modo: "o homem 
não afirma a sua subsistência e o seu valor de pessoa senão quando afirma, ao mesmo tempo, a subsistência e o valor de pessoa dos homens a ele coexistentes, e concebe, quer e põe entre si e estes um vínculo de recíproco reconhecimento e de respeito". 23

Deste modo, a afirmação da minha condição pessoal, associada ao valor que dela decorre, é contemporânea e coligada à afirmação da condição pessoal dos outros em sociedade. O eu afirma-se como sujeito de direito somente quando reconhece os outros como subsistentes jurídicos, como sujeitos de direito merecedores do mesmo respeito do qual se julga digno. A personalidade jurídica é, portanto, um conceito relacional, que envolve a pessoa alheia do mesmo modo como o direito do ego não pode ser pensado desvinculado do direito do alter, sendo, por consequência, despropositada toda forma de individualismo supressor dessa sociabilidade originária.

Disso Petrone conclui que a relação de justiça é uma avaliação comparativa do ego e do alter segundo uma ideia de distinção co-respectiva e igualdade recíproca. $\mathrm{O}$ ego percebe-se e dimensiona-se pelo alter em razão de similitudes e de diferenças, mas sempre a partir de um valor igual: "percebe e avalia o outro como seu socius; não como mais nem como menos; não como superior nem como inferior; o apreende e avalia como seu par: eis tudo". ${ }^{24}$

É a razão pela qual o sujeito, dimensionando o outro como um ser de valor igual, se dispõe a circunscrever sua liberdade de modo a não prejudicar a mesma esfera de liberdade dos coexistentes, evitando atribuir a si mesmo prerrogativas que não reconheceria como necessárias para a esfera de atuação social dos demais. Esta lei de limitação, pela qual ego e alter se reconhecem e se limitam reciprocamente à luz de um ideal comum, o socius, é a gênese da liberdade formal compreendida como exigência de não impedimento, que Petrone considera ser o princípio constitutivo do direito, o conteúdo essencial da juridicidade. ${ }^{25}$

Giorgio Del Vecchio, seguindo um caminho próximo ao trilhado por Petrone, expõe que o ser subjetivo (o eu), com consciência de si, contrapõe-se necessariamente aos objetos do mundo, os quais entram na esfera da sua consciência como "não-eu". Mas o sujeito também se relaciona com outro sujeito, sendo capaz de reconhecê-lo como um "outro eu", como alguém de igual valor, nascendo deste movimento do espírito a ideia de alteridade.

Assim, além da consciência de si ou autoconsciência, há também uma "consciência de si em forma objetiva, pela qual a subjetividade se projeta em uma coordenação" ${ }^{26}$ Este movimento da consciência não é uma faculdade que se possa recusar, pois responde a uma profunda vocação do espírito humano, pela qual o sujeito é capaz de perceber que, estando ligado aos demais na coexistência, deve coordenar sua ação com as ações alheias segundo uma ponderação objetiva do direito, cuja exigência fundamental é que "todo sujeito seja reconhecido (pelos outros) pelo que vale, e que a cada um seja atribuído (pelos outros) o que merece". ${ }^{27}$ 
A justiça, portanto, tem lugar quando um eu reconhece outro sujeito não como um objeto, mas como um outro eu também consciente de sua posição subjetiva, e ambos se dispõem a limitar, de modo bilateral, paritário e recíproco, suas personalidades de modo a permitir o livre desenvolvimento da personalidade de todos na vida social. Por isto, a exigência de justiça existe apenas entre seres humanos e se pode defini-la como o "princípio de coordenação entre seres subjetivos". ${ }^{28}$

Para Guido Calogero, a sociedade é uma contínua neutralização das desigualdades, um caminhar sucessivo da injustiça à justiça. Ao mesmo tempo em que afirma a natural desigualdade (de força, talento, habilidades etc.) dos homens, reúne esforços para a realização da igualdade, que não deve ser pensada como planificação, como achatamento das personalidades e conversão das pessoas em seres rigorosamente iguais, mas como "o equilíbrio das fruições de mundo, o equilíbrio das liberdades". ${ }^{29}$

Em outras palavras: a justiça, como exigência ética, não deve eliminar as diferenças que existem entre os seres humanos, mas possibilitar que cada um tenha as condições necessárias para que, em igualdade com os demais, possa buscar sua auto-realização pela ação da liberdade. A justiça não quer, portanto, suprimir a desigualdade natural, mas viabilizar uma igualdade social a partir da qual todas as pessoas possam se afirmar como verdadeiramente livres. É neste sentido que, kantianamente, se pode defini-la como "a convivência das liberdades". ${ }^{30}$

Comentando a posição de Calogero, Eugenio Garin afirma que a justiça sempre esteve ligada à sociabilidade e à alteridade, nascendo desta vinculação a ideia de uma regra que age sobre a sociedade no intuito de conservá-la. A esta noção primária de justiça como legalidade logo se opôs outra, a da justiça como protesto contra a lei injusta. Contra um formalismo vazio que sustenta leis mesmo quando estas instituam discriminações abusivas, afirma-se historicamente a justiça como defensora de uma natureza humana, pela qual todas as pessoas são livres e iguais.

Disto, porém, decorre uma nova aporia, pois por natureza os homens são profundamente desiguais. Assim, ao buscar o "tratamento proporcional à condição de cada um”, a justiça quer preservar uma igualdade não dada, mas desejada, para que todos possam "igualmente afirmar sua liberdade em uma coordenação de homens" e, nos limites das condições humanas, "ninguém faça aos outros aquilo que não quer que os outros lhe façam". ${ }^{31}$

É próprio da natureza humana, diz Garin, a dignidade que os homens reconhecem uns nos outros como seres igualmente livres. Liberdade que pretendem assegurar pela ação da justiça. Esta, portanto, pode ser definida como o "esforço de harmonizar e fazer convergir a própria liberdade com a dos outros como liberdades pares na integralidade da própria humanidade (...)”. 32

Recentemente, Francesco D’Agostino escreveu páginas que ecoam as concepções de Petrone, Del Vecchio e Calogero. Assim como estes autores, ele 
também vincula a justiça à pessoa. Por mais que existam visões variadas sobre esta conexão, afirma, todas concordam em um ponto essencial, o reconhecimento, princípio que impõe a qualquer ordem jurídica o tratamento do ser humano como uma pessoa dotada de dignidade e, neste sentido, não merecedora de discriminações arbitrárias ou injustas. Por isto, o jurista deve ter em mente que "o princípio do reconhecimento se converte no princípio constitutivo do direito (ou, caso se prefira, no seu pressuposto necessário), isto é, no princípio da igualdade". ${ }^{33}$ São justas, portanto, as restrições de condutas em prol de uma liberdade igual, e injustas as que estabelecem tratamentos privilegiados ou discriminatórios que violam a necessária fraternidade que deve vigorar entre os homens.

Destas considerações sobre pessoa e reconhecimento podemos extrair um dado axiológico objetivo inerente à justiça: a dimensão de liberdade igual dos seres humanos. A justiça é a virtude que deve viabilizar esta condição, pela via da coexistência recíproca juridicamente organizada. Assim, uma norma ou um ordenamento que violem este valor são objetivamente injustos, ao contrário do sustentado por Kelsen, Ross e Perelman.

Por isto, uma norma que estabeleça um tratamento discriminatório a alguém em razão, por exemplo, de sua origem ou religião, proibindo-a de entrar em certos espaços abertos ao público, não é apenas arbitrária, mas francamente injusta. O reconhecimento do valor igual das pessoas não é uma atitude emocional comprometida com certos interesses em detrimento de outros igualmente possíveis, mas "a condição fundamental de toda possível forma de existência verdadeiramente humana". ${ }^{34}$

\section{CONSIDERAÇÕES FINAIS}

Diante do exposto, pode-se dimensionar adequadamente a posição axiológica irracionalista de Kelsen, Ross e Perelman. A meu ver, eles têm razão quando apontam a regularidade como exigência constitutiva da juridicidade. Aplicar uma norma imparcialmente aos integrantes da classe ou categoria essencial aos quais ela se destina, de acordo com o critério distintivo escolhido, é uma imposição da ideia de justiça e, como tal, atende ao que Perelman chama de "regra da razão". Mas, para estes autores, a racionalidade da justiça se exaure nessa exigência. Os valores nos quais as normas se apóiam são sempre relativos ao sujeito que os estima e, neste sentido, traduzem pretensões emocionais insuscetíveis de arbitramento racional. Assim, pensada como valor, a justiça é um ideal irracional.

Uma reflexão mais detida sobre a questão, porém, pode levar à seguinte indagação: por que a aplicação de uma norma com regularidade aos seus destinatários é uma exigência racional e, neste sentido, justa? Não seria porque os seres humanos que integram uma categoria essencial (pessoas de certa faixa etária, do mesmo sexo, da mesma profissão etc.), em sua condição pessoal, são iguais? E, neste caso, a ação de tratá-los desigualmente violaria sua igualdade ontológica? 
Se a dignidade é o valor que decorre do reconhecimento recíproco de uma liberdade igual, então este valor é uma objetividade que não pode ser transgredida. Segue-se que um ordenamento que institua uma discriminação que o viole é objetivamente injusto, e não somente para quem o valore negativamente. Penso, portanto, que Kelsen, Ross e Perelman perceberam corretamente que não há juridicidade sem sua concretização regular, mas não que isto decorre de uma objetividade, o reconhecimento da liberdade igual (ou dignidade).

Com esta percepção, a racionalidade da justiça como aplicação regular de normas ganha um fundamento: a igualdade ontológica das pessoas. Este é o valor objetivo que o direito deve necessariamente realizar, pois, não o fazendo, afasta-se de sua vocação ética e converte-se em ordem injusta, em tirania. Sem o reconhecimento desta condição de viabilidade do homem como sujeito digno, não se tem o "direito como direito", na expressão de Castanheira Neves, mas somente uma ordem normativa funcionalista, para a qual a pessoa nunca passará de mero instrumento ou objeto. ${ }^{35}$

\section{REFERÊNCIAS}

CALOGERO, Guido. Intorno al concetto di giustizia. Argomenti, I, n. 5-6, p. 2-21, 1941.

CASTANHEIRA NEVES, A. O direito hoje e com que sentido? O problema actual da autonomia do direito. Lisboa: Instituto Piaget, 2002.

COTTA, Sergio. Il diritto nell'esistenza. Linee di ontofenomenologia giuridica. 2. ed. Milano: Giuffrè, 1991.

D'AGOSTINO, Francesco. Di che cosa parliamo, quando parliamo di giustizia? In: Valori giuridici fondamentali. Roma: Aracne, p. 27-37, 2010.

DEL VECCHIO, Giorgio. La giustizia. Roma: Studium, 1946.

GARIN, Eugenio. Giustizia. Revue Internationale de Philosophie, v. 41, p. 268-301, 1957.

KELSEN, Hans. Las metamoforsis de la idea de justicia. In: CAIRNS et al. El actual pensamiento juridico norteamericano. Buenos Aires: Losada, p. 245 299, 1951.

. O problema da justiça. São Paulo: Martins Fontes, 1998.

PERELMAN, Chaïm. De la justice. In: Justice et raison. 2. ed. Bruxelles: Editions de l'Université de Bruxelles, p. 9-80, 1972.

PETRONE, Igino. Il diritto nel mondo dello spirito. Milano: Libreria Editrice Milanese, 1910.

ROSS, Alf. Sobre el derecho y la justicia. 3. ed. Buenos Aires: Eudeba, 2011. 
SANTIAGO NINO, Carlos. Justicia. In: VALDÉS, Ernesto Garzón; LAPORTA, Francisco J. (Org.) El derecho y la justicia. Madrid: Trotta, p. 467-480, 1996.

SFORZA, Widar Cesarini. Il problema della giustizia. Rivista Internazionale di Filosofia del Diritto, a. 38, p. 46-54, 1961.

1 SANTIAGO NINO, Carlos. Justicia. In: VALDÉS, Ernesto Garzón; LAPORTA, Francisco J. (Org.) EI derecho y la justicia. Madrid: Trotta, 1996, p. 467.

2 KELSEN, Hans. O problema da justiça. São Paulo: Martins Fontes, 1998, p. 4.

3 KELSEN, Hans. Las metamoforsis de la idea de justicia. In: CAIRNS et al. El actual pensamiento juridico norteamericano. Buenos Aires: Losada, 1951, p. 251.

4 Ibid., p. 251.

5 Ibid., p. 261.

6 Ibid., p. 262.

7 Ibid., p. 263.

8 ROSS, Alf. Sobre el derecho y la justicia. 3. ed. Buenos Aires: Eudeba, 2011, p. 334.

9 Ibid., p. 335 .

10 Ibid., p. 338.

11 Ibid., p. 339.

12 Ibid., p. 340.

13 Ibid., p. 340.

14 Ibid., p. 346.

15 Ibid., p. 346.

16 PERELMAN, Chaïm. De la justice. In: Justice et raison. 2. ed. Bruxelles: Editions de l'Université de Bruxelles, 1972, p. 26.

17 SFORZA, Widar Cesarini. Il problema della giustizia. Rivista Internazionale di Filosofia del Diritto, a. 38,1961, p. 48.

18 PERELMAN, Chaïm, op. cit., p. 64.

19 Ibid., p. 71.

20 Ibid., p. 75.

21 Ibid., p. 77-78.

22 PETRONE, Igino. Il diritto nel mondo dello spirito. Milano: Libreria Editrice Milanese, 1910, p. 40.

23 Ibid., p. 45.

24 Ibid., p. 46.

25 Ibid., p. 195.

26 DEL VECCHIO, Giorgio. La giustizia. Roma: Studium, 1946, p. 83-84.

27 Ibid., p. 90.

28 Ibid., p. 3.

29 CALOGERO, Guido. Intorno al concetto di giustizia. Argomenti, I, n. 5-6, 1941, p. 15.

30 Ibid., p. 15.

31 GARIN, Eugenio. Giustizia. Revue Internationale de Philosophie, v. 41, 1957, p. 300.

32 Ibid., p. 301.

33 D'AGOSTINO, Francesco. Di che cosa parliamo, quando parliamo di giustizia? In: Valori giuridici fondamentali. Roma: Aracne, 2010, p. 34.

34 COTTA, Sergio. Il diritto nell'esistenza. Linee di ontofenomenologia giuridica. 2. ed. Milano: Giuffrè, 1991, p. 209.

35 CASTANHEIRA NEVES, A. O direito hoje e com que sentido? O problema actual da autonomia do direito. Lisboa: Instituto Piaget, 2002, p. 72. 


\title{
THE RATIONALITY OF JUSTICE
}

\begin{abstract}
This paper discusses the concepts of Hans Kelsen, Alf Ross and Chaïm Perelman on justice as regularity in the application of the Law, and as subjective and irrational value, in order to show its insufficiency as a descriptor of the Law. Contrarily to what these authors say, Law must be guided by an axiological objectivity, equal liberty or dignity, mutually recognized within social coexistence. The disdain or ignorance of this objective value converts Law in an unfair and functionalist order, capable of legitimizing discrimination as a valid expression of subjectivity not bound to the test of reason. The recognition of man as a person is a sound requirement of rationality of justice, without which it is not possible to arise the necessary ethical vocation of Law.
\end{abstract}

Keywords: Justice. Person. Recognition. Dignity.

Submetido: 7 dez. 2015

Aprovado: 5 jan. 2016 